\title{
Histoplasmose pulmonar canina no estado de Pernambuco, Brasil: relato de caso
}

\author{
[Canine pulmonary histoplasmosis in Pernambuco State, Brazil: case report]
}

T.I.B. Silva, A.C.B. Silva, M.E.Z. Muñoz, L.M.V. Zubieta, F.E.V. Zubieta, M.J.G. Silva

Universidade Federal Rural de Pernambuco - UFRPE - Recife, PE

\begin{abstract}
RESUMO
A histoplasmose é uma das principais doenças micóticas que acometem o trato respiratório inferior de pequenos animais, sendo ocasionada pelo Histoplasma capsulatum, fungo encontrado em solos ricos em compostos nitrogenados, derivados de matéria orgânica em decomposição. Descreve-se um caso de histoplasmose pulmonar em um canino da raça Boxer, domiciliado no estado de Pernambuco, Brasil, o qual apresentava uma síndrome respiratória com evolução clínica de aproximadamente seis meses. Na análise citopatológica do lavado broncoalveolar, foram visualizadas estruturas leveduriformes de aproximadamente dois micrômetros de diâmetro, características de $H$. capsulatum, sendo, então, indicada a terapia com itraconazol. O exame citopatológico do lavado broncoalveolar é uma ferramenta diagnóstica importante na identificação do agente, e o tratamento com itraconazol é eficiente, levando à remissão completa dos sinais clínicos.
\end{abstract}

Palavras-chave: fungo, respiratório, cão, lavado broncoalveolar, citopatologia

\begin{abstract}
Histoplasmosis is a main fungal diseases that affect the lower respiratory tract of small animals, being caused by Histoplasma capsulatum, a fungus found in soil rich in nitrogen compounds, derived from decaying organic matter. It is described a case of pulmonary histoplasmosis in a dog of Boxer breed, domiciled in the state of Pernambuco, Brazil, which had a respiratory syndrome with clinical course of about six months. On cytopathological examination of bronchoalveolar lavage were visualized yeast structures of approximately two micrometers in diameter, characteristics of $H$. capsulatum, and then was indicated therapy with itraconazole. The cytopathological examination of bronchoalveolar lavage is an important diagnostic tool in the identification of the agent and the treatment with itraconazole is efficient, leading to complete remission of clinical signs.
\end{abstract}

Keywords: Fungus, respiratory, dog, bronchoalveolar lavage, cytopathology

\section{INTRODUÇÃO}

As infecções pulmonares representam casos frequentes na rotina da clínica médica dos animais domésticos. A histoplasmose é uma das principais doenças micóticas que acometem o trato respiratório inferior de pequenos animais (Bromel e Sykes, 2005), podendo também ocorrer em humanos (Deus Filho et al., 2009), sendo considerada uma zoonose. A doença é ocasionada pelo Histoplasma capsulatum, fungo dimórfico, que, ao penetrar no organismo por inalação, se converte da forma micelial para a leveduriforme, fase infectante (Capone et al., 2011).

Esse micro-organismo é encontrado em solos ricos em compostos nitrogenados, derivados de matéria orgânica em decomposição, sobretudo excretas de morcegos e aves, seja em locais abertos ou em cavernas. Sua propagação e viabilidade podem perdurar por vários anos, desde que em regiões com $\mathrm{pH}$ de solo ácido, médias de temperatura mais baixas e elevada umidade relativa do ar (Clinkenbeard et al., 1987).

Recebido em 10 de agosto de 2012

Aceito em 25 de junho de 2013

E-mail: tamyres_ibs@hotmail.com 
Embora referida como de distribuição geográfica mundial, a ocorrência da histoplasmose tem maior frequência em zonas tropicais, subtropicais e temperadas. No Brasil, a doença foi pouco relatada nos animais domésticos, havendo escassos registros na região nordeste (Brilhante et al., 2012).

Além da afecção pulmonar, a histoplasmose pode ser manifestada sob as formas gastroentérica, óssea, ocular e tegumentar, porém a infecção respiratória possui maior importância na clínica médica dos caninos (Kerl, 2003; Bromel e Sykes, 2005). Os sinais clínicos observados em cães com histoplasmose pulmonar correspondem à inapetência, emagrecimento, febre, aumento de volume dos linfonodos cervicais e axilares, dispneia, tosse e estertores pulmonares à ausculta. Determinados animais ainda podem desenvolver a infecção subclínica (Ferreira et al., 2007).

Estudos anteriores citam uma predisposição das raças Pointer, Weimaraner e Brittany Spaniel (Scott et al., 1996). No entanto, pesquisas mais recentes demonstram que a doença não está correlacionada à predisposição racial (Bromel e Sykes, 2005), mas a faixa etária parece ser um fator importante, em que cães com idade inferior a quatro anos estão mais susceptíveis à infecção (Clinkenbeard et al., 1987).

A abordagem diagnóstica é estabelecida por meio da anamnese e exame clínico do paciente, associados aos exames complementares, tais como estudo radiográfico, broncoscopia, ensaios imunoenzimáticos, testes moleculares, microbiológicos e alergocutâneos (Guimarães et al., 2006). As análises citopatológica e histopatológica das vias aéreas inferiores, além de fornecerem o diagnóstico etiológico, bem como a elucidação do mecanismo da doença, são as técnicas que apresentam maior sensibilidade. A identificação do $H$. capsulatum é baseada na avaliação morfológica do fungo, na qual são visualizadas estruturas leveduriformes arredondadas, de 2 a $4 \mu \mathrm{m}$ de diâmetro, com núcleo púrpuro e protoplasma ligeiramente basofílico, circundado por um halo delgado e claro (Hawkins e DeNicola, 1990).

Os principais fármacos empregados na conduta terapêutica em cães são os derivados imidazólicos, principalmente o itraconazol, na dose de $10 \mathrm{mg} / \mathrm{kg}$, com intervalo de 24 horas e duração de aproximadamente seis meses (Capone et al., 2011). O cetoconazol e a anfotericina B também são indicações úteis (Mitchell e Stark, 1980), mas atualmente essas drogas apresentam o uso limitado, visto seu maior potencial de toxicidade no organismo.

Neste contexto, objetivou-se descrever um caso de histoplasmose pulmonar em um cão, domiciliado no estado de Pernambuco, Brasil, ratificando a importância do estudo citopatológico do lavado broncoalveolar (LBA) como ferramenta diagnóstica.

\section{CASUÍSTICA}

Um canino, da raça Boxer, macho, com quatro anos de idade, pesando $30 \mathrm{~kg}$, foi atendido no período de agosto de 2011, com queixa de tosse recorrente. O cão era domiciliado em um sítio no bairro de Aldeia, município de Camaragibe, estado de Pernambuco, Brasil, onde foi relatada ainda a livre circulação de morcegos no local.

Na anamnese, o proprietário descreveu que o cão apresentava uma síndrome respiratória, com evolução clínica de aproximadamente seis meses, culminando em hiporexia, perda de peso progressiva, intolerância ao exercício físico e discretos episódios de êmese.

$\mathrm{O}$ animal havia sido atendido anteriormente em outras três clínicas veterinárias, onde realizou exames complementares, tais como hemograma e radiografia torácica, sendo então submetido a um tratamento para broncopneumonia parasitária, alérgica e bacteriana, respectivamente. Diante da ausência de resposta satisfatória em meio aos protocolos terapêuticos empregados e à falta da elucidação da etiopatogenia da síndrome clínica apresentada pelo cão, o proprietário buscou nova assistência médico-veterinária pela quarta ocasião, na qual o paciente foi reavaliado.

No exame clínico, observou-se secreção nasal bilateral sero-sanguinolenta, dispneia, tosse seca, sibilos à auscultação pulmonar, prostração, conjuntivite e discreta desidratação. Solicitou-se hemograma, radiografia torácica, nas projeções ventro-dorsal e lateral, exame citopatológico e microbiológico de LBA. 
Para a colheita do LBA, o animal foi sedado com diazepam, na dose de $30 \mathrm{mg}$, associado ao propofol, na dose de $120 \mathrm{mg}$, ambos pela via endovenosa, em bolus. Posteriormente, o cão foi posicionado em decúbito esternal, com a cabeça em angulação de 45 graus, para ser submetido a uma sondagem endotraqueal, pela qual infundiuse $20 \mathrm{~mL}$ de solução salina morna estéril e recuperou-se aproximadamente $4 \mathrm{~mL}$ (Hawkins e DeNicola, 1990; Cowell et al., 2009).

A amostra do lavado foi fracionada em três alíquotas, a serem encaminhadas à análise citopatológica, pela coloração tipo Romanowsky, ao cultivo bacteriológico, em ágar sangue ovino desfibrinado, e micológico, em ágar Sabouraud com cloranfenicol, realizados em cabine de segurança biológica.

No hemograma (Tab. 1), quanto à série branca, verificou-se um aumento discreto do número de células da linhagem neutrofílica (bastonetes e segmentados) e monocítica, além de linfopenia e eosinopenia. $\mathrm{O}$ eritrograma, a contagem de trombócitos e a dosagem de proteínas plasmáticas se encontravam dentro da normalidade para a espécie.

O estudo radiográfico do tórax revelou pequenos nódulos radiopacos, distribuídos aleatoriamente nos campos pulmonares e padrão intersticial evidente (Fig. 1).
Na citopatologia do LBA (Fig. 2), identificaramse células colunares ciliadas e não ciliadas, cubóides não ciliadas e caliciformes, inúmeros macrófagos alveolares, neutrófilos e linfócitos, placas mucoides eosinofílicas e espirais de Curschmann. Não foram visualizadas células displásicas ou neoplásicas. Observaram-se, ainda, estruturas leveduriformes arredondadas, de aproximadamente $2 \mu \mathrm{m}$ de diâmetro, com núcleo púrpuro e protoplasma ligeiramente basofílico, circundado por um delgado halo claro, características de Histoplasma capsulatum. $\mathrm{O}$ resultado do cultivo bacteriológico e micológico da mesma amostra foi negativo.

Sendo assim, foi instituído um protocolo terapêutico à base de itraconazol $(10 \mathrm{mg} / \mathrm{kg} / 24$ horas), via oral, durante quatro meses, a princípio, sendo o paciente reavaliado mensalmente nesse período. Foram prescritos ainda complexo vitamínico, xarope expectorante à base de acetilcisteína $(10 \mathrm{mg} / \mathrm{kg} / 12$ horas $/ 10$ dias) e amoxicilina associada ao clavulanato de potássio $(10 \mathrm{mg} / \mathrm{kg} / 12$ horas/21 dias), pela via oral.

Ao término de aproximadamente três meses, o animal apresentou remissão do quadro clínico, sendo recomendados mais 30 dias de terapia com o antifúngico na mesma dose, encerrando o tratamento em seguida, tendo em vista a ausência de estruturas fúngicas na nova avaliação citopatológica do LBA nesse período.

Tabela 1. Avaliação hematológica de um canino da raça Boxer, com diagnóstico de histoplasmose pulmonar

\begin{tabular}{|c|c|c|c|c|}
\hline Índices & \multicolumn{2}{|c|}{ Resultado } & \multicolumn{2}{|c|}{ Valores de referência* } \\
\hline Hemácias & \multicolumn{2}{|c|}{$5,5 \times 10^{6} / \mathrm{mm}^{3}$} & \multicolumn{2}{|c|}{$5,5-8,5 \times 10^{6} / \mathrm{mm}^{3}$} \\
\hline Hemoglobina & \multicolumn{2}{|c|}{$12,6 \mathrm{~g} / \mathrm{dL}$} & \multicolumn{2}{|c|}{$12-18 \mathrm{~g} / \mathrm{dL}$} \\
\hline Hematócrito & \multicolumn{2}{|c|}{$38,0 \%$} & \multicolumn{2}{|c|}{$37-55 \%$} \\
\hline VCM & \multicolumn{2}{|c|}{$69,1 \mathrm{fL}$} & \multicolumn{2}{|c|}{$60-77 \mathrm{fL}$} \\
\hline $\mathrm{CHCM}$ & \multicolumn{2}{|c|}{$33,2 \%$} & \multirow{2}{*}{\multicolumn{2}{|c|}{$\begin{array}{c}32-36 \% \\
6-17 \times 10^{3} / \mathrm{mm}^{3}\end{array}$}} \\
\hline Leucócitos & \multicolumn{2}{|c|}{$16,4 \times 10^{3} / \mathrm{mm}^{3}$} & & \\
\hline Bastonetes & $6 \%$ & $984 / \mathrm{mm}^{3}$ & $0-3 \%$ & $0-300 / \mathrm{mm}^{3}$ \\
\hline Segmentados & $78 \%$ & $12.792 / \mathrm{mm}^{3}$ & $60-77 \%$ & $3.000-11.500 / \mathrm{mm}^{3}$ \\
\hline Eosinófilos & $1 \%$ & $164 / \mathrm{mm}^{3}$ & $2-4 \%$ & $200-1.250 / \mathrm{mm}^{3}$ \\
\hline Linfócitos & $5 \%$ & $820 / \mathrm{mm}^{3}$ & $12-30 \%$ & $1.000-4.800 / \mathrm{mm}^{3}$ \\
\hline Monócitos & $10 \%$ & $1.640 / \mathrm{mm}^{3}$ & $3-10 \%$ & $150-1.350 / \mathrm{mm}^{3}$ \\
\hline Plaquetas & \multicolumn{2}{|c|}{$262.300 / \mathrm{mm}^{3}$} & \multicolumn{2}{|c|}{$200-500 / \mathrm{mm}^{3}$} \\
\hline Proteínas plasmáticas & \multicolumn{2}{|c|}{$7,6 \mathrm{~g} / \mathrm{dL}$} & \multicolumn{2}{|c|}{$6-8 \mathrm{~g} / \mathrm{dL}$} \\
\hline
\end{tabular}

$\mathrm{VCM}=$ volume corpuscular médio; $\mathrm{CHCM}=$ concentração hemoglobínica corpuscular média.

* Kaneko et al., (1997). 


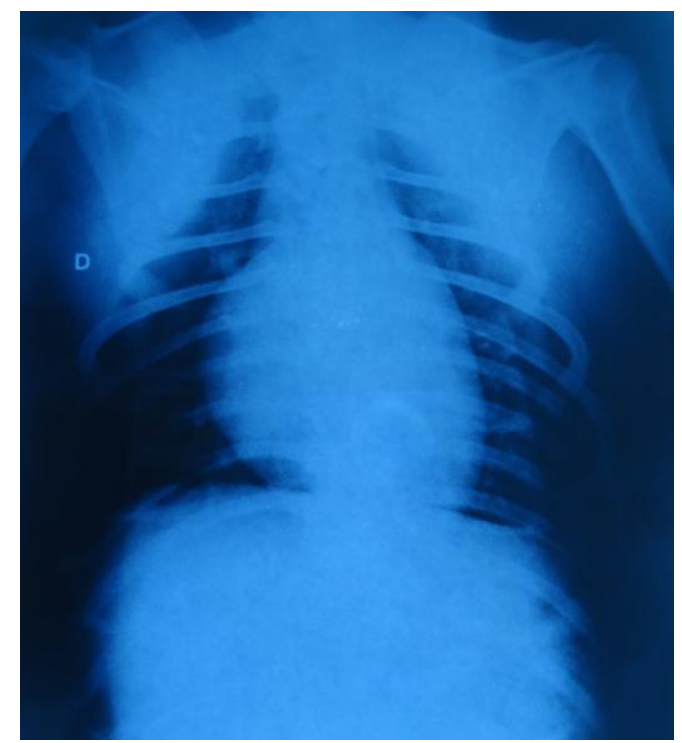

Figura 1. Exame radiográfico da região torácica de um canino da raça Boxer, com diagnóstico de histoplasmose pulmonar

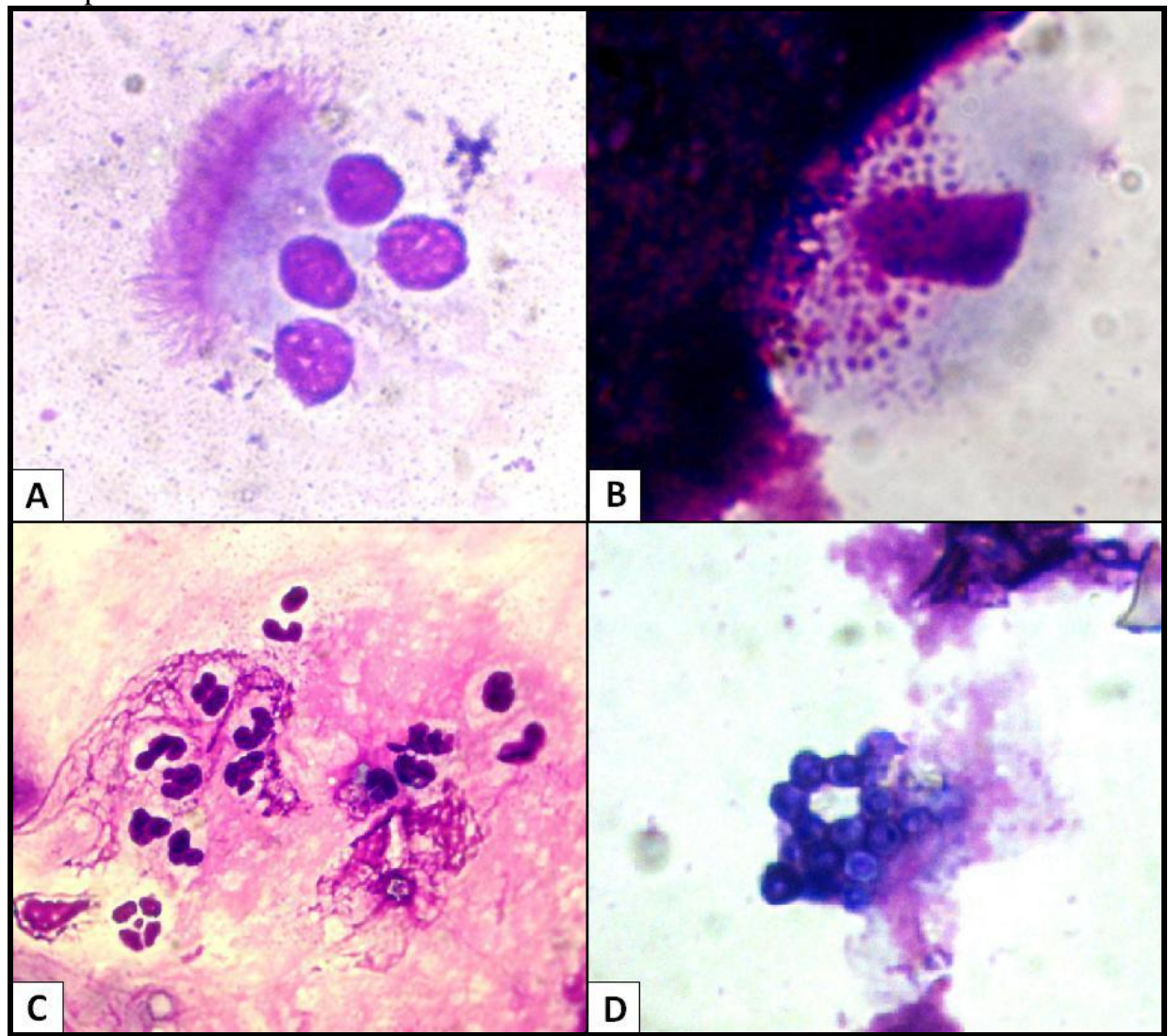

Figura 2. Análise citopatológica de lavado broncoalveolar de um canino da raça Boxer com diagnóstico de histoplasmose pulmonar. A) Células colunares ciliadas (aumento de 1000x); B) célula caliciforme (aumento de 1000x); C) células inflamatórias e material mucóide (aumento de 400x); D) Estruturas leveduriformes arredondadas, em meio extracelular, de aproximadamente $2 \mu \mathrm{m}$ de diâmetro, com núcleo púrpuro e protoplasma basofílico, circundado por um halo delgado e claro, características de Histoplasma capsulatum (aumento de 1000x). Coloração tipo Romanowsky. 


\section{DISCUSSÃO}

O crescimento e a disseminação do $H$. capsulatum estão diretamente associados à temperatura, umidade e $\mathrm{pH}$ do ambiente. Animais expostos naturalmente a essas condições têm elevada probabilidade de adquirirem a infecção (Capone et al., 2011). Neste relato, a localização da residência do paciente, considerada como uma zona de microclima, a circulação de morcegos no local e o livre acesso do animal ao solo constituíram um ambiente favorável à ocorrência da histoplasmose. Além disso, o canino encontravase dentro da faixa etária de risco, de acordo a Ferreira et al. (2007).

O $H$. capsulatum, ao atingir o sistema reticuloendotelial, desencadeia uma inflamação piogranulomatosa, composta por linfócitos, neutrófilos e macrófagos, principais componentes imunológicos envolvidos na defesa primária contra $\mathrm{o}$ agente. $\mathrm{O}$ aumento dessas células no LBA, associado à presença de material mucoide e espirais de Curschmann, são alterações compatíveis com processos mais crônicos das vias aéreas (Cowell et al., 2009).

De forma similar, as células caliciformes não são comumente encontradas em LBA, mas qualquer irritante pulmonar crônico pode resultar na elevação da quantidade desses componentes. Porém, células colunares e cuboides são achados normais nesse tipo de amostra (Hawkins e DeNicola, 1990).

A análise citopatológica de LBA, sobretudo de cães na fase aguda, apresenta valor diagnóstico; porém, a aspiração do parênquima pulmonar aumenta a possibilidade de detecção do agente, visto que existe uma predileção do $H$. capsulatum por se alojar principalmente no interstício pulmonar (Cowell et al., 2009). Apesar disso, a técnica empregada no caso relatado e a cronicidade do processo não impediram a visualização das leveduras.

Guimarães et al. (2006) e Capone (2011) citam o cultivo microbiológico de amostras das vias aéreas como definitivo no diagnóstico da histoplasmose pulmonar, por apresentar alta sensibilidade, porém esse procedimento não é muito recomendado devido ao potencial patogênico do $H$. capsulatum para os manipuladores. Neste estudo, o exame citopatológico do LBA demonstrou maior sensibilidade, comparado ao cultivo fúngico, corroborando, dessa forma, com Hawkins e DeNicola (1990), não havendo a necessidade de confirmação por isolamento (Kerl, 2003).

Com relação aos aspectos hematológicos, sabe-se que cães com histoplasmose pulmonar, embora não se tenha observado no caso, podem apresentar anemia normocítica e normocrômica, de grau intermediário, podendo estar associada à supressão da eritropoese, devido à infecção medular pelo agente ou citocinas liberadas no decurso da doença em estágio crônico (Mitchell e Stark, 1980; Thrall, 2006).

A linfopenia pode ser elucidada pela presença de esteroides endógenos, também liberados no estresse da doença crônica, resultando em imunossupressão da produção dessas células. $\mathrm{O}$ aumento discreto de neutrófilos bastonetes e segmentados não descaracteriza a cronicidade do processo, mas pode representar fases de reagudização (Cowell et al., 2009).

Quanto à convalescência ao $H$. capsulatum, esta tem sido relacionada à resposta imunológica dos animais enfermos. Embora a doença seja considerada autolimitante, a discussão ainda é controversa (Capone et al., 2011). No caso descrito, por exemplo, não houve resolução espontânea do quadro clínico, sendo necessária a administração de antifúngico oral. Contudo, de acordo a Clinkenbeard et al. (1987), a infecção das vias aéreas em caninos apresenta um prognóstico bom, permitindo uma resposta terapêutica satisfatória, diferentemente do que ocorre em felinos (Brilhante et al., 2012).

\section{CONCLUSÕES}

O exame citopatológico do lavado broncoalveolar é uma ferramenta diagnóstica importante na identificação do Histoplasma capsulatum e o tratamento com itraconazol é eficiente, levando à remissão completa dos sinais clínicos. 


\section{REFERÊNCIAS}

BRILHANTE， R.S.N.; COELHO, C.G.V.; SIDRIM, J.J.C. et al. Feline Histoplasmosis in Brazil: Clinical and Laboratoty Aspects and a Comparative Approach of Published Reports. Mycopathol., v.2-3, p.193-197, 2012.

BROMEL, C.; SYKES, J. Histoplasmosis in dogs and cats. Clin. Tech. Small An. P. v.20, p.227-32, 2005.

CAPONE, D.; JANSEN, J.M.; LOPES, A.J. et al. Micoses pulmonares. Rev. Hosp. Univ. Pedro Ernesto, v.14, p.72-80, 2011.

CLINKENBEARD， K.D.; COWELL， R.L.; TYLER, R.D. Disseminated histoplasmosis in cats: 12 cases (1981-1986). J. Am. Vet. Med. Assoc., v.190, p.1445-1448, 1987.

COWELL, R.L.; TYLER, R.D.; MEINKOTH, J.H.; DENICOLA, D.B. Diagnóstico citológico e hematologia de cães e gatos. 3.ed. São Paulo: MedVet, 2009. 476p.

DEUS FILHO, A.; WANKE, B.; CAVALCANTI, M.A.S. et al. Histoplasmose no Nordeste do Brasil. Relato de três casos. Rev. Port. de Pneumol., v.15, p.109-114, 2009.
FERREIRA， R.R.; MACHADO, M.L.S.; SPANAMBERG, A. et al. Infecções fúngicas do trato respiratório de cães e gatos. Acta Sci. Vet., v.35, p.285-288, 2007.

GUIMARÃES， A.J.; NOSANCHUK， J.D.; ZANCOPÉ-OLIVEIRA, R.M. Diagnosis of Histoplasmosis. Braz. J. Microbiol., v.37, p.1-13, 2006.

HAWKINS, E.C.; DENICOLA, D.B. Cytologic analysis of tracheal wash specimens and bronchoalveolar lavage fluid in the diagnosis of mycotic infections in dog. J. Am. Vet. Med. Assoc., v.197, p.79-83, 1990.

KERL, M.E. Update on canine and feline fungal diseases. Vet. Clin. N. Am-Small, v.33, p.721747, 2003.

MITCHELL, M.; STARK, D.R. Disseminated canine histoplasmosis: A clinical survey of 24 cases in Texas. Can. Vet. J., v.21, p.95-100, 1980.

SCOTT, D.W; MILLER, W.H.; GRIFFIN, C.E. Dermatologia de pequenos animais. 5.ed. Rio de Janeiro: Interlivros, 1996. 1130p.

THRALL, M.A. Hematologia e Bioquímica Clínica Veterinária. São Paulo: Roca, 2006. 582p. 